\title{
Gastrointestinal angiodysplasia is associated with significant gastrointestinal bleeding in patients with continuous left ventricular assist devices
}

Authors

Institutions
Justin Cochrane ${ }^{1}$, Christian Jackson ${ }^{2}$, Greg Schlepp ${ }^{3}$, Richard Strong ${ }^{2}$

Institutions are listed at the end of article. submitted:

1. June 2015

accepted after revision:

5. January 2016

\section{Bibliography}

DOI http://dx.doi.org/

10.1055/s-0042-101752

Endoscopy International Open 2016; 04: E371-E377

(c) Georg Thieme Verlag KG Stuttgart . New York

E-ISSN 2196-9736

Corresponding author Justin Cochrane, DO 4320 W Deska Dr Apt 109 Spokane, WA 99224 Phone: +1-513-418-1788 justincg5@yahoo.com Justin.cochrane@providence. org
Background and study aims: Patients with a continuous-flow left ventricular assist device (LVAD) have a $65 \%$ incidence of bleeding events within the first year. The majority of gastrointestinal bleeding (GIB) is from gastrointestinal angiodyplasia (GIAD). The primary aim of the study was to determine whether GIAD was associated with a higher rate of significant bleeding, an increased number of bleeding events per year, and a higher rate of transfusion compared to non-GIAD sources.

Patients and methods: This retrospective cohort study included 118 individuals who received a LVADat a tertiary medical center from 2006 through 2014. Patients were subdivided into GIB and non-GIB for comparison of patient demographics, comorbid conditions, and laboratory data. GIB was further divided into sources of GIB, GIAD, obscure, or non-GIAD to establish severity of bleeding, rate of re-bleeding, and transfusion rate.

\section{Introduction \\ $\nabla$}

Left ventricular assist device (LVAD) usage is projected to escalate in accordance with the rising incidence of end stage heart failure (ESHF), fueled by improved survival when compared to optimal medical therapy [1]. Gastrointestinal bleeding (GIB) has been associated with LVAD in up to $65 \%$ within the first year [2], with a mortality rate of $9 \%[3,4]$. Gastrointestinal angiodysplasia (GIAD) is a common source of bleeding with LVAD [5-8]. The primary aim of the study was to compare the characteristics of GIADversus non-GIAD patients in 118 patients with LVAD and describe the differences in the clinical presentation between the two groups.
Results: GIADis associated with an increased number of bleeding events compared to nonGIAD sources of GIB (2.07 vs $1.23, P=0.01)$ and a higher number of bleeding events per year (0.806 vs. $0.455 P=0.001$ ). GIAD compared to non-GIAD sources of GIB was associated with an increased incidence of major bleeding (100\% vs $60 \%, P=0.006)$ and increased rates of transfusion (8.8 vs 2.95 units, $P=0.0004$ ). Cox Regression analysis between non-GIB and GIAD demonstrated increased risk with age $(P=0.001)$, history of chronic kidney disease $(P=0.005)$, and length of stay after LVADimplantation of more than 45 days $(P=0.04)$. History of hypertension $(P=$ 0.045), diabetes mellitus $(P=0.016)$, and male gender was associated with decreased risk $(P=$ 0.04).

Conclusion: Patients with a continuous-flow LVAD who develop a GIB secondary to GIAD have a higher rate of major bleeding, multiple bleeding events, and require more transfusions to achieve stabilization compared to patients who do not have GIAD.

\section{Patients and methods \\ $\nabla$}

We reviewed data from 118 adult patients (>18 years) who underwent a continuous flow Heartmate II LVADimplantation (Thoratec Corp., Pleasanton,CA) for ESHF over an 8-year time span (2006-2014). These patients were retrospectively evaluated utilizing electronic medical records (Meditech, Epic), at a tertiary referral center, Providence Sacred Heart Medical Center. Patients were excluded if they received a pulsatile LVAD, heart transplant within 30 days, or died within 2 weeks of implantation. The Institutional Review Board associated with Providence Sacred Heart Medical Center approved the collection and review of data at their institution for the purpose of this study by the primary author. 
Continuous flow LVAD support was initiated for patients with severe heart failure associated with compromised left ventricular cardiac function as a bridge to transplant (BTT) or as destination therapy (DT), in patients deemed not to be candidates for transplantations. Postoperative anticoagulation included unfractionated heparin and later transitioned to warfarin therapy with an international normalized ratio (INR) goal of 2-3. All patients were placed on $81 \mathrm{mg}$ aspirin after implantation. Intravenous proton pump inhibitor (PPI) therapy was initiated for all patients and they were transitioned to oral PPI therapy once extubated. Continuation of PPI therapy was left up to the cardiothoracic surgeon after patients were transferred out of the intensive care unit (ICU).

Initial identification of patients with GIB was conducted by searching key terms: melena, hematochezia, or bright red blood per rectum. A secondary search was conducted for guaiac-positive stool, or new or worsening anemia. Positive results on initial search led to a review of endoscopic procedure notes. GIB was defined as overt or occult from the time of implantation of the LVAD until transplantation or death. Overt GIB was defined as melena, hematochezia, hematemesis or coffee ground emesis. Occult bleeding was defined as iron deficiency anemia, worsening anemia without overt signs, or a positive fecal occult blood test. Obscure bleeding was defined as overt bleeding with no source identified with EGD or colonoscopy. Bleeding was categorized as either upper gastrointestinal tract (esophagus to the first portion of the duodenum) or lower gastrointestinal (distal to the ligament of Treitz to the rectum). Determination of the source of GIB was made via review of endoscopic procedure notes for GIAD, Non-GIAD, and obscure GIB. Patients with GIAD, obscure bleeds, and non-GIAD were assessed for severity of bleeding, average number of repeat bleeding events, and average number of transfusions required per patient. Severity of bleeding was broken down into major and minor. Major bleeding was defined as an $\mathrm{Hgb}$ change of greater than $4 \mathrm{~g} / \mathrm{dL}$ or transfusion given. Minor bleeding was defined as an Hgb change of less than $4 \mathrm{~g} / \mathrm{dL}$ with no transfusion given. Blood bank records were reviewed in the GIB population to determine the number of units transfused with each bleeding event.

All endoscopic procedures were performed in either the ICU or inpatient endoscopy suite. Conscious sedation (fentanyl, midazolam) or monitored anesthesia was administered at the discretion of the endoscopist and consulting anesthesiologist. Patients underwent upper endoscopy, colonoscopy, and single balloon enteroscopy at Providence Sacred Heart Medical Center. Endoscopic treatment modalities for control of bleeding included injection of epinephrine, thermal therapy (bipolar or monopolar electrocautery, argon plasma laser), or hemostatic clips. Determination of treatment modalities to control bleeding was left to the discretion of the performing endoscopist. Anticoagulation and antiplatelet therapy was discontinued until active GIB ceased. After cessation of active GIB the decision to restart anticoagulation and antiplatelet therapy was left to the discretion of the cardiothoracic surgeon.

Demographics were reviewed with attention to the following parameters: clinical features of congestive heart failure, prior GIB, antiplatelet therapy, PPI therapy, comorbid conditions (chronic kidney disease (CKD), diabetes mellitus (DM), hypertension (HTN), pack years smoking, initial length of stay (LOS), percentage of patients with initial LOS greater than $75^{\text {th }}$ percentile (45 days), INR, creatinine, and platelets counts. If mortality oc- curred during the study period, the causes was determined from electronic medical records at our institution.

\section{Statistical Analysis}

Continuous variables were expressed as a mean \pm standard deviation and categorical data as N (\%). Cox Regression analysis was performed to identify factors independently associated with GIAD in patients receiving LVAD support. A two-tailed $t$-test was performed to determine significance of the means between groups and Pearson chi-squared test or Fischer exact test when appropriate was used to compare categorical data between groups with a $P$ value $<0.05$ being significant. The BenjaminiHochberg procedure was utilized to confirm $P$ values calculated from multiple statistical tests were of true significance. Confidence intervals are reported at 95\%. (SPSS IBM version 22).

\section{Results \\ $\nabla$}

\section{Patients}

A total of 118 patients underwent LVADimplantation from 2006 through 2014. Of them, 22 were excluded leaving 96 patients to be evaluated, 56 patients in the non-GIB group and 40 patients in the GIB group ( $\bullet$ Fig. 1 ). $\bullet$ Table 1 lists demographics of NonGIB and GIB groups. The incidence of GIB over an 8-year period was $41.7 \%$. All GIB was diagnosed with EGD, colonoscopy or sin-

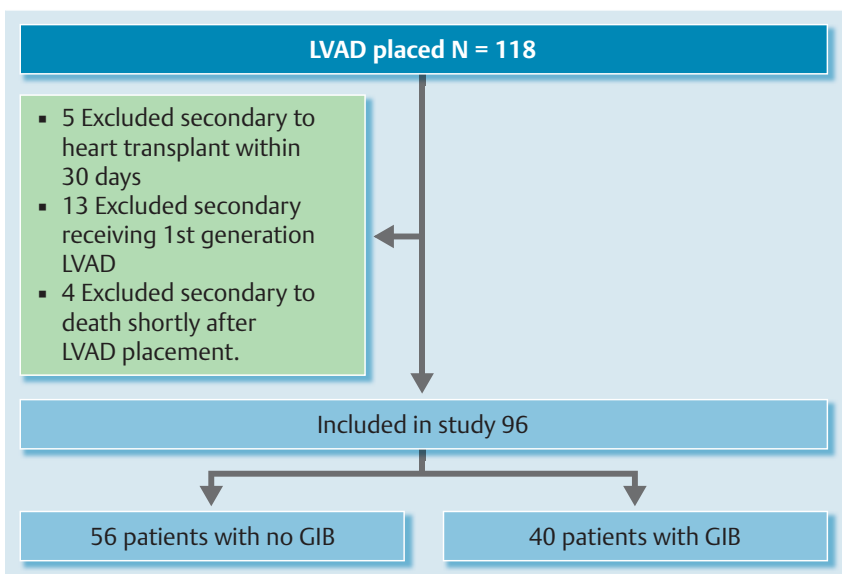

Fig. 1 Distribution of patients

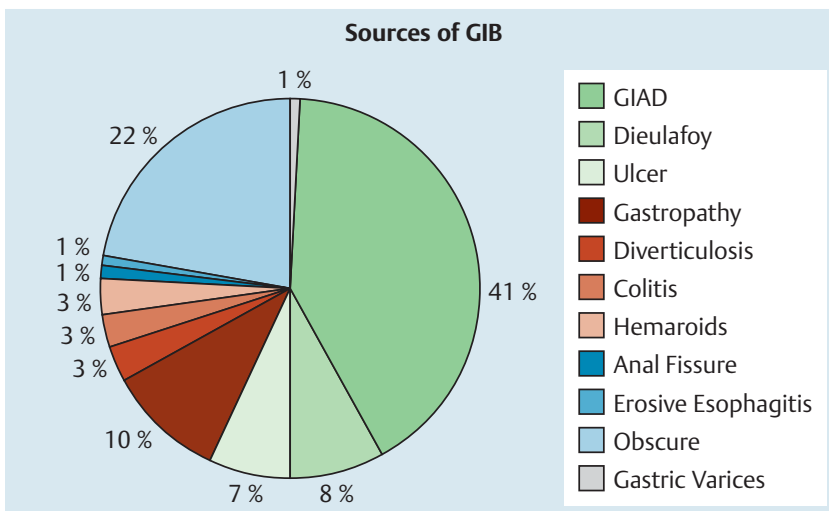

Fig. 2 Sources of gastrointestinal bleeding in patients with continuous flow LVAD 


\begin{tabular}{|c|c|c|c|}
\hline Demographics & $\begin{array}{l}\text { Non-gastrointestinal bleed } \\
(n=56)\end{array}$ & Gastrointestinal bleed $(n=40)$ & $\begin{array}{l}\text { Significance } \\
(P \text { value })\end{array}$ \\
\hline Age (years) & $\begin{array}{l}54.4 \pm 10.5 \\
\mathrm{Cl}(51.8-57.0)\end{array}$ & $\begin{array}{l}58.8 \pm 13.4 \\
\mathrm{Cl}(54.5-63.1)\end{array}$ & 0.055 \\
\hline Sex (male \%) & 84 & 76 & 0.232 \\
\hline CKD (\%) & 42 & 52 & 0.418 \\
\hline $\mathrm{DM}(\%)$ & 55 & 36 & 0.073 \\
\hline HTN (\%) & 42 & 31 & 0.089 \\
\hline Pack years & $\begin{array}{l}16.8 \pm 26 \\
\mathrm{Cl}(10.2-23.4)\end{array}$ & $\begin{array}{l}12.7 \pm 20 \\
\mathrm{Cl}(6.1-19.36)\end{array}$ & 0.24 \\
\hline LOS days & $\begin{array}{l}37.7 \pm 18.6 \\
\mathrm{Cl}(32.7-42.7)\end{array}$ & $\begin{array}{l}48.9 \pm 23 \\
(41.4-56.4)\end{array}$ & 0.13 \\
\hline Average CR (mg/dL) & $\begin{array}{l}1.52 \pm 0.84 \\
\mathrm{Cl}(1.32-1.72)\end{array}$ & $\begin{array}{l}1.42 \pm 0.52 \\
\mathrm{Cl}(1.25-1.59)\end{array}$ & 0.48 \\
\hline Average INR & $\begin{array}{l}2.28 \pm 0.46 \\
\mathrm{Cl}(2.17-2.39)\end{array}$ & $\begin{array}{l}2.3 \pm 0.57 \\
\mathrm{Cl}(2.12-2.48)\end{array}$ & 0.93 \\
\hline Average PIt $\left(10^{9} / \mathrm{L}\right)$ & $\begin{array}{l}214 \pm 64 \\
\mathrm{Cl}(198-230)\end{array}$ & $\begin{array}{l}201 \pm 59 \\
\mathrm{Cl}(183-220)\end{array}$ & 0.155 \\
\hline Average $\mathrm{Hgb}(\mathrm{mg} / \mathrm{dL})$ & $\begin{array}{l}12.0 \pm 1.1 \\
\mathrm{Cl}(11.7 \text { to } 12.3\end{array}$ & $\begin{array}{l}9.9 \pm 1.26 \\
\mathrm{Cl}(9.49-10.3)\end{array}$ & 0.001 \\
\hline Ischemic cardiomyopathy & 72 & 55 & 0.051 \\
\hline Non-ischemic cardiomyopathy & 28 & 45 & 0.08 \\
\hline Bridge to transplant (\%) & 75 & 65 & 0.376 \\
\hline Destination therapy (\%) & 25 & 35 & 0.376 \\
\hline INTERMACS Levels (\%) & 1.8 & 2.5 & 0.02 \\
\hline 1 & 34 & 40 & 0.40 \\
\hline 2 & 45 & 27.5 & 0.46 \\
\hline 3 & 9 & 17.5 & 0.30 \\
\hline $\begin{array}{l}4 \\
5\end{array}$ & 11 & 12.5 & 0.37 \\
\hline $\mathrm{PPI} \%$ prior to GIB & 57 & 80 & 0.005 \\
\hline ASA $\%$ & 60 & 18 & 0.0001 \\
\hline Prior GIB (\%) & 5 & 5 & 0.691 \\
\hline $\begin{array}{l}\text { Prior GIAD (\% prior to LVAD } \\
\text { implantation) }\end{array}$ & 0 & 0 & 1 \\
\hline Mortality (\%) & 10 & 10 & 1 \\
\hline Ethnicity & $\begin{array}{l}90 \% \text { Caucasian, } 3 \% \text { African } \\
\text { American, } 3 \% \text { Hispanic }\end{array}$ & $\begin{array}{l}90 \% \text { Caucasian, } 5 \% \text { African } \\
\text { American, and } 5 \% \text { Hispanic }\end{array}$ & $>0.05$ \\
\hline
\end{tabular}

Abbreviations: CKD, chronic kidney disease; DM, diabetes mellitus; HTN, hypertension; LOS, length of stay; CR, creatinine; INR, international normalized ratio; PLT, platelets; GIB, gastrointestinal bleed; Cl, confidence Interval; PPI, proton pump inhibitor; GIAD, gastrointestinal angiodysplasia

$\mathrm{N}$ equals the number of patients in groups.

gle balloon enteroscopy. GIAD was the most common diagnosis for GIB (๑ Fig.2).

\section{Etiology of gastrointestinal bleeding}

When initial episodes were evaluated, the number of episodes between GIAD and non-GIAD were similar (29 vs 29). However, GIAD had a higher rate of rebleeding episodes and a higher frequency of bleeding events each year when compared to nonGIAD. Patients diagnosed with GIAD compared to non-GIAD had a lower INR, higher incidence of major bleeding, and increased rate of transfusions ( $\bullet$ Table 2 ). There was no difference between GIAD and non-GIAD in LVAD implantation to first GIB ( $\bullet$ Table 1 ). The majority of GIAD was diagnosed in the upper gastrointestinal tract as compared to the lower gastrointestinal tract, (65\% vs 35 $\%$ ). The distribution for non-GIAD lesions between the upper and lower gastrointestinal tract was similar to that for GIAD, $56 \%$ and $44 \%$, respectively. All-cause mortality was $10 \%$ with $2 \%$ directly related to GIB ( $\bullet$ Table 1$)$.

When GIAD was evaluated separately, there was no significant difference observed in severity of bleeding, number of bleeding events, and transfusion rate between GIAD of the upper and lower gastrointestinal tract $(\bullet$ Table 3$)$.

The difference between the non-GIB and GIB was significant for average baseline Hgb, PPI use, and aspirin use ( $\bullet$ Table 1 ). The GIB patient population utilizing PPI therapy prior to GIB was 80 $\%$ with and additional $8 \%$ starting PPI therapy for treatment of GIB episodes. The GIB patient population utilizing PPI therapy prior to GIB was significant compared to non-GIB ( $\bullet$ Table 1 ). When patients diagnosed with GIAD were individually compared to non-GIB, significance was demonstrated for age, and initial LOS ( Table4). Cox Regression analysis between non-GIB and GIAD demonstrated increased risk with age, history of CKD, and length of stay after LVADimplantation of greater than 45 days. Risk was decreased in patients who had a history of HPN, DM or who were male ( $\bullet$ Table 5$)$. 


\begin{tabular}{|c|c|c|c|}
\hline Demographics & $\operatorname{GIAD}(n=14)$ & Non-GIAD $(n=22)$ & Significance ( $P$ value) \\
\hline Age (years) & $\begin{array}{l}65.7 \pm 6.5 \\
\mathrm{Cl}(62.0-69.5)\end{array}$ & $\begin{array}{l}58.6 \pm 12 \\
\mathrm{Cl}(53.06-64.1)\end{array}$ & 0.57 \\
\hline Sex (male \%) & 66 & 72 & 0.72 \\
\hline CKD (\%) & 60 & 54 & 1 \\
\hline $\mathrm{DM}(\%)$ & 33 & 22 & 0.46 \\
\hline HTN (\%) & 33 & 40 & 1 \\
\hline Pack years & $\begin{array}{l}11.2 \pm 18.8 \\
\mathrm{Cl}(0.4-22)\end{array}$ & $\begin{array}{l}13.4 \pm 19 \\
\mathrm{Cl}(5.0-21.8)\end{array}$ & 0.744 \\
\hline LOS (days) & $\begin{array}{l}51 \pm 20 \\
\mathrm{Cl}(39.3-62.7)\end{array}$ & $\begin{array}{l}45.2 \pm 17 \\
\mathrm{Cl}(37.6-52.8)\end{array}$ & 0.362 \\
\hline Average creatinine $(\mathrm{mg} / \mathrm{dL})$ & $\begin{array}{l}1.56 \pm 0.53 \\
\mathrm{Cl}(1.25-1.87)\end{array}$ & $\begin{array}{l}1.42 \pm 0.55 \\
\mathrm{Cl}(1.08-1.76)\end{array}$ & 0.47 \\
\hline Average INR & $\begin{array}{l}2.09 \pm 0.43 \\
\mathrm{Cl}(1.84-2.34)\end{array}$ & $\begin{array}{l}2.5 \pm 0.59 \\
\mathrm{Cl}(2.24-2.76)\end{array}$ & 0.029 \\
\hline Average Plt $\left(10^{9} / \mathrm{L}\right)$ & $\begin{array}{l}206 \pm 60 \\
C l(171-241)\end{array}$ & $\begin{array}{l}199 \pm 61 \\
\mathrm{Cl}(172-226)\end{array}$ & 0.742 \\
\hline \# bleeding episodes & $\begin{array}{l}2.07 \pm 1.3 \\
\mathrm{Cl}(1.27-2.87)\end{array}$ & $\begin{array}{l}1.22 \pm 0.52 \\
\mathrm{Cl}(0.99-1.45)\end{array}$ & 0.01 \\
\hline Bleeding events per year & $0.806 \pm 0.74(\mathrm{Cl} 0.42-1.2)$ & $0.455 \pm 0.21(\mathrm{Cl} 0.37-0.55)$ & 0.001 \\
\hline Major bleeds (\%) & 100 & 60 & 0.006 \\
\hline Minor Bleeds \% & 21 & 40 & 0.29 \\
\hline Days till first bleed & $\begin{array}{l}189 \pm 174 \\
\mathrm{Cl}(89-289)\end{array}$ & $\begin{array}{l}203 \pm 182 \\
C I(123-283)\end{array}$ & 0.82 \\
\hline Units Transfused & $\begin{array}{l}8.8 \pm 5.1 \\
\mathrm{Cl}(5.9-11.7)\end{array}$ & $\begin{array}{l}2.95 \pm 3.7 \\
\mathrm{Cl}(1.3-4.6)\end{array}$ & 0.0004 \\
\hline
\end{tabular}

Table 2 Comparison between GIAD and non-GIAD in continuous LVAD patient population.

Abbreviations: chronic kidney disease (CKD), diabetes mellitus (DM), hypertension (HTN), length of stay (LOS), creatinine (CR), International normalized ratio (INR), platelets (PLT), gastrointestinal (GI), Confidence Interval (Cl). Major bleeding Hgb change of greater than $4 \mathrm{~g} / \mathrm{dL}$ or transfusion given. Minor bleeding $\mathrm{Hgb}$ change of less than $4 \mathrm{~g} / \mathrm{dL}$ with no transfusion given. $\mathrm{N}$ equals the number of patients per group.

\begin{tabular}{|llll} 
& Upper GIAD $(\mathbf{n = 1 1 )}$ & Lower GIAD $(\mathbf{n}=\mathbf{4})$ & Significance $(\boldsymbol{P}$ value $)$ \\
\hline Average number of & $1.87 \pm 0.67$ & $1.6 \pm 0.81$ & 0.9 \\
bleeding events & $\mathrm{Cl}(1.42-2.32)$ & $\mathrm{Cl}(0.31-2.89)$ & 1 \\
\hline Major bleeds (\%) & 100 & 100 & 1 \\
\hline Minor bleeds 9\%) & 0 & 0 & 0.9 \\
\hline Units transfused/person & $9.2 \pm 5.4$ & $7 \pm 6.5$ & \\
& $\mathrm{Cl}(5.4-13)$ & $\mathrm{Cl}(0-23)$ &
\end{tabular}

Table 3 Comparison between upper GIAD and lower GIAD.

Abbreviations: GIAD, gastrointestinal angiodysplasia; GIB, gastrointestinal bleeding; $\mathrm{Cl}$, confidence interval $\mathrm{N}$ equal number of patients in groups.

\section{Discussion}

Limited data exist on comparisons of patients with continuous flow LVAD who were diagnosed with GIADversus a non-GIAD source with regard to severity of bleeding, rate of repeat bleeding, and number of transfusions required, thus determining the true impact of GIAD.

The mechanism for increased GIB in continuous flow LVAD patients is considered to be multifactorial. The reasons include but are not limited to: shear force from the rotor apparatus causing decreased von Willebrand factor (vWF) similar to the proposed mechanism in aortic stenosis (Heyde's syndrome) [9]; elimination of pulse pressure variation by the continuous flow causing diminished gut perfusion and ischemia [10]; and mandatory use of anticoagulation to prevent thromboembolism [11].

We report a $41.7 \%$ incidence of GIB after LVAD implantation, with the majority of the episodes occurring in the upper gastrointestinal tract, irrespective of GIAD or a non-GIAD source (65\% \& $55 \%$ ). We diagnosed GIAD in $41 \%$ of bleeding episode, which is similar to the published literature, and the majority of GIAD events were found in the upper gastrointestinal tract (65\%) [12-14]. Bleeding episodes secondary to GIAD required an average of 8 units of
PRBC whereas non-GIAD bleeding episodes required an average 3 units of PRBC. Forty-two percent of patients with GIAD had repeat bleeding episodes (average of 2 ), compared to $18 \%$ nonGIAD (average of 1.22). Patients diagnosed with GIADaveraged close to one bleeding event per year, while patients with nonGIADaveraged one bleeding event every 2 years. We feel that one of the consequences of rebleeding episodes in patients diagnosed with GIAD is that they will require a high number of transfusions, potentially exposing potential heart transplant candidates to unwanted alloantibodies, and could result in increased hospitalization.

Establishing predictors for patients who are at high risk for the development of GIAD could potentially reduce the increased burden of bleeding episodes in terms of hospitalization and quality of life. Patients with a continuous flow LVAD have a high rate of readmission within the first 30 days for decompensated heart failure (47\%) followed by GIB (22\%) [15]. Patients readmitted with GIB have an average LOS of 7 days $[15,16]$. Previous studies have demonstrated that elderly patients and a history of CKD are associated with a higher relative risk of GIB with a continuous flow LVAD[12]. Similar predictors have been identified in patients diagnosed with GIAD without LVAD[17]. Our data demon- 
Table 4 Comparison between non-GIB \& GIB subdivided into GIAD and obscure, and non-GIAD sources.

\begin{tabular}{|c|c|c|c|c|c|}
\hline Demographics & Non-GIB $(n=56)$ & $\operatorname{GIAD}(n=14)$ & Non-GIAD(n=22) & Obscure $(n=14)$ & $\begin{array}{l}\text { Significance } \\
\text { ( } P \text { value) }\end{array}$ \\
\hline Age (years) & $\begin{array}{l}54.4 \pm 10.5 \\
\mathrm{Cl}(51.8-57.0)\end{array}$ & $\begin{array}{l}65.7 \pm 6.5 \\
\mathrm{Cl}(62.0-69.5)\end{array}$ & $\begin{array}{l}58.6 \pm 12 \\
\mathrm{Cl}(53.1-64.1)\end{array}$ & $\begin{array}{l}57.1 \pm 16 \\
\mathrm{Cl}(48.0-66.2)\end{array}$ & $0.001,0.2,0.57$ \\
\hline Sex m (\%) & 84 & 66 & 72 & 71 & $0.14,0.35,0.3$ \\
\hline CKD (\%) & 42 & 60 & 54 & 47 & $0.15,0.35,0.76$ \\
\hline DM (\%) & 55 & 33 & 22 & 42 & $0.47,0.054,0.55$ \\
\hline HTN (\%) & 42 & 33 & 40 & 35 & $\begin{array}{l}0.232,0.314 \\
0.77\end{array}$ \\
\hline Pack years & $\begin{array}{l}16.8 \pm 26 \\
\mathrm{Cl}(10.2-23.4)\end{array}$ & $\begin{array}{l}11.2 \pm 18.8 \\
\mathrm{Cl}(0.4-22)\end{array}$ & $\begin{array}{l}13.4 \pm 19 \\
\mathrm{Cl}(5-21.8)\end{array}$ & $\begin{array}{l}7.85 \pm 21 \\
\mathrm{Cl}(0-20.11)\end{array}$ & $\begin{array}{l}0.461,0.58, \\
0.001\end{array}$ \\
\hline LOS (days) & $\begin{array}{l}37.7 \pm 18.6 \\
\mathrm{Cl}(32.7-42.7)\end{array}$ & $\begin{array}{l}51 \pm 20 \\
\mathrm{Cl}(39.3-62.7)\end{array}$ & $\begin{array}{l}45.2 \pm 17 \\
\mathrm{Cl}(37.6-52.8)\end{array}$ & $\begin{array}{l}52.2 \pm 29 \\
\mathrm{Cl}(35-69.4)\end{array}$ & $\begin{array}{l}0.02,0.094, \\
0.001\end{array}$ \\
\hline Average CR (mg/dL) & $\begin{array}{l}1.52 \pm 0.84 \\
(C I 1.32-1.72)\end{array}$ & $\begin{array}{l}1.56 \pm 0.53 \\
\mathrm{Cl}(1.25-1.87)\end{array}$ & $\begin{array}{l}1.42 \pm 0.55 \\
\mathrm{Cl}(1.08-1.76)\end{array}$ & $\begin{array}{l}1.3 \pm 0.35 \\
\mathrm{Cl}(1.12-1.48)\end{array}$ & $0.87,0.67,0.03$ \\
\hline Average INR & $\begin{array}{l}2.28 \pm 0.46 \\
\mathrm{Cl}(2.17-2.39)\end{array}$ & $\begin{array}{l}2.09 \pm 0.43 \\
\mathrm{Cl}(1.84-2.34)\end{array}$ & $\begin{array}{l}2.5 \pm 0.59 \\
\mathrm{Cl}(2.24-2.76)\end{array}$ & $\begin{array}{l}2.2 \pm 0.44 \\
\mathrm{Cl}(1.77-2.43)\end{array}$ & $\begin{array}{l}0.181,0.095 \\
0.17\end{array}$ \\
\hline Average PIt $\left(10^{9} / \mathrm{L}\right)$ & $\begin{array}{l}214 \pm 64 \\
\mathrm{Cl}(198-230)\end{array}$ & $\begin{array}{l}206 \pm 60 \\
\mathrm{Cl}(171-241)\end{array}$ & $\begin{array}{l}199 \pm 61 \\
\mathrm{Cl}(172-226)\end{array}$ & $\begin{array}{l}217 \pm 64 \\
\mathrm{Cl}(184-250)\end{array}$ & $0.698,0.372,1$ \\
\hline
\end{tabular}

Abbreviations: CKD, chronic kidney disease; DM, diabetes mellitus; HTN, hypertension; LOS, length of stay; CR, creatinine; INR, international normalized ratio; PLT, platelets; $\mathrm{GI}(\mathrm{PLT})$, gastrointestinal $(\mathrm{GI})$, Confidence Interval $(\mathrm{CI})$. N equals the number of patients in each group. Key for $\mathrm{p}$ value interpretation: $1^{\text {st }} \mathrm{P}$ Value comparing Non-GIB vs $\mathrm{GIAD}$, 2nd p value comparing Non-GIB vs Non-GIAD, 3 rd p value comparing Non-GIB vs obscure bleeding.

strate a similar predictive value for GIAD in elderly patients and patients with a history of CKD ( $\bullet$ Table 5$)$.

Cox Regression analysis demonstrates that patients with an initial LOS after LVAD implantation of greater than 45 days are at 5 times higher risk of developing a GIAD during our study period and should have close follow up with prompt endoscopic intervention with signs of GIB in order to reduce the high rate of admission for this population ( $\bullet$ Table 5 ).

Prompt endoscopic interventions to identify and treat GIADare crucial to help reduce the severity of bleeding and LOS. Sarosiek et al. [18] evaluated the impact of prompt endoscopic treatment of GIAD with a low threshold for performing enteroscopy after initial workup with EGD and colonoscopy were negative, similar to the approach used for diagnosis and treatment of obscure GIB. This strategy leads to a decreased rate of transfusions. The longterm success for this strategy is unclear. Further studies must be performed to determine if this endoscopic strategy is successful in LVAD patients. Initial endoscopic treatment for GIAD in the non-LVAD patient population has done little to prevent recurrence of GIAD with $34 \%$ having repeat bleeding episodes [17].

Previous investigators have suggested that the high rates of bleeding are secondary to a defect in thrombogenesis secondary to non-pulsatile flow in continuous flow LVADs [19]. Non-pulsatile flow can cause decreased levels of vWF, which leads to an acquired vWF syndrome. In addition, there is evidence to suggest that vWF may play a role in angiogenesis via vascular endothelial growth factors receptor-2 (VEGFR2) [20], thus causing new formation of GIAD.

Vascular endothelial growth factor (VEGF) is perhaps the most highly recognized pro-angiogenic protein that plays a crucial role in the early phases of angiogenesis [20]. The system of angiopoietins, namely Ang- 1 and Ang-2, and the Tie-2 receptor are similarly required for regulating the later phase of angiogenesis, specifically the maturation and stability of newly formed blood vessels [20]. Ang-2 antagonistically binds to the Tie-2 receptor as a competitive inhibitor of Ang-1 in order to prime the vascular endothelium for activation and destabilization, and in so doing, acts synergistically with VEGF to promote angiogenesis [20,21].
Starke et al. [22] have demonstrated that blocking vWF function increases the release of Ang-2 from intracellular stores both in vitro as well in a chimeric model. Furthermore, integrin $\alpha v \beta 3$ is the most well-known endothelial cell receptor for vWF and has been characterized as having both pro-angiogenic as well as antiangiogenic functions [20]. There is evidence that $\alpha v \beta 3$ function is decreased in vWF deficient endothelial cells, which has also been associated with increased level of VEGFR2 dependent angiogenesis [23] ( Fig.3). Although there is evidence to show there is no difference in vWF levels between patients with GIAD and controls [24], vWF deficiency or loss of HMWM may be transient in nature, therefore, quantitative measurement of these factors is potentially unreliable. VEGF is expressed on colonic GIADand has therefore been a target of therapy for GIAD [25,26]. Future studies are needed to determine if the use of treatment strategies aimed at inhibiting VEGF after endoscopic intervention could reduce the rate of repeat bleeding episodes.

Table 5 Cox regression analysis demonstrating hazard ratios for non-GIB vs GIAD.

\begin{tabular}{|c|c|c|c|}
\hline & $\begin{array}{l}\text { Hazard } \\
\text { ratio }\end{array}$ & $\begin{array}{l}\text { Confidence interval } \\
(95 \%)\end{array}$ & $\begin{array}{l}\text { Significance } \\
\text { ( } P \text { value) }\end{array}$ \\
\hline Age & 1.3 & 1.12 to 1.59 & 0.001 \\
\hline Sex (male) & 0.11 & 0.013 to 0.91 & 0.040 \\
\hline CKD & 21.0 & 2.49 to 181 & 0.005 \\
\hline DM & 0.89 & 0.012 to 0.64 & 0.016 \\
\hline $\begin{array}{l}\text { Pack years } \\
\text { smoking }\end{array}$ & 1.03 & 0.99 to 1.07 & 0.088 \\
\hline HTN & 0.219 & 0.05 to 0.97 & 0.045 \\
\hline LOS $>45$ days & 5.06 & 1.08 to 23.7 & 0.04 \\
\hline Creatinine (avg) & 0.68 & 0.095 to 4.8 & 0.70 \\
\hline INR (avg) & 0.99 & 0.25 to 4.04 & 0.99 \\
\hline Platelet (avg) & 1.0 & 0.99 to 1.01 & 0.95 \\
\hline
\end{tabular}

Abbreviations: GIB, gastrointestinal bleed; GIAD, gastrointestinal angiodysplasia; CKD, chronic kidney disease; DM, diabetes mellitus; HTN, hypertension; LOS, length of stay; INR, international normalized ratio; avg, average

LOS $>45$ days is the initial LOS after left ventricular device implanted, GIB, and GIAD. 
vWf inactivation

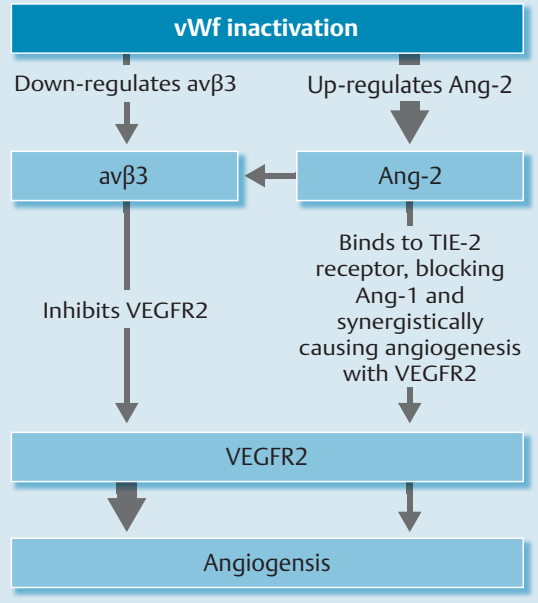

Fig. 3 How inactivation of von Willebrand creased angiogenesis and gastrointestinal angiodysplasia in patients with continuous flow LVAD. factor leads to in-

The vast majority of patients with a continuous flow LVAD were prescribed long-term antiplatelet therapy to reduce the risk of thromboembolic events. Antiplatelet therapy is associated with an increased risk of developing GIB by irreversibly inhibiting platelet function for the life span of the platelets and disrupting prostaglandin synthesis, thus exposing the gastric mucosa to high acid concentrations. Several randomized controlled trials demonstrated that PPIs decreased GIB risk for patients on antiplatelet drugs by $60 \%$ for average risk patients and $89 \%$ for those patients with prior GIB [13]. Similar to Kushnir et al, [13] 88\% of patients in GIB group in our study were taking PPI therapy. Multivariate analysis demonstrated that patients with LVAD on PPI therapy were 14 times more likely to have a GIB. Because the GIB population has a higher chance of developing a GIB on PPI therapy, that suggests that additional mechanisms for mucosal damage are occurring other than antiplatelet effects on the gastric mucosa.

An additional defense mechanism in the gastric mucosa is the mucosal microcirculation, which removes acid and noxious substances from the gastric mucosa. In order to remain functional, the mucosal microcirculation needs adequate perfusion and prostaglandin synthesis. Impaired mucosal microcirculation allows for back diffusing of hydrogen ions, thus allowing for greater mucosal damage from lower acid concentrations. This hypothesis of back diffusion of hydrogen ions has been observed in critically ill patients [27]. Critically ill patients have reduced gastrointestinal circulation even if systolic blood pressure is normotensive secondary to autoregulation. The continuous flow LVAD device has an effect similar to stress-related mucosal bleeding (SRMB) in critically ill patients, in that the continuous flow device eliminates pulse pressure variation causing decreased perfusion of the gastrointestinal tract. This defect in microcirculation could explain why LVAD patients are more prone to bleeding episodes despite being on prophylactic PPI therapy. The role of antiplatelet therapy and an impaired gastric microcirculation is unclear in the development of GIAD.

Several limitations of this study should be noted. First, this was a single-center retrospective cohort study performed at Providence Sacred Heart Medical Center, which can entail a selection bias. Secondly, several patients were observed to have more than one source of GIB and may have been included in one or more groups. Third, the determination to transfuse red blood cell units was physician-dependent and not based on parameters of Hgb less than $7 \mathrm{~g} / \mathrm{dL}$ as was seen in other studies. Finally, we did not measure vWF activity and we could only hypothesize its role in the pathogenesis of GIB in the LVAD patient population.

In conclusion, GIB secondary to GIAD occurs at lower INR levels, is associated with a higher percentage of all GIB, and requires more transfusions when compared to non-GIAD bleeding sources. Our data support closer outpatient monitoring for rebleeding, prompt endoscopic intervention in patients with GIAD, and use of a lower INR range for anticoagulation. More randomized controlled trials are needed to evaluate a difference between prompt endoscopic interventions versus endoscopic intervention in addition to the use of a VEGF antagonist.

\section{Competing interests: None.}

\section{Institutions}

${ }^{1}$ Assistant Clinical Associate Professor University of Washington Medical School, Providence Sacred Heart Medical Center

Internal Medicine Residency Spokane, Washington, United States

2 Loma Linda University Medical Center, Department of Medicine, Section of Gastroenterology, Loma Linda, California, United States

3 Spokane Digestive Disease Center Spokane, Washington, United States

\section{References}

1 Miller LW, Pagnani ED, Russell SD et al. Use of continuous-flow devices in patients awaiting heart transplant. NEJM 2007; 357: 885-896

2 Crow S, Chen D, Milano $C$ et al. Acquired von Willebrand syndrome in continuous-flow ventricular assist device recipients. Ann Thorac Surg 2010; 90: 1263 - 1269

3 John $R$, Kamdar F, Liao $K$ et al. Improved survival and decreasing incidence of adverse events with the HeartMate II left ventricular assist device as bridge-to-transplant therapy. Ann Thorac Surg 2008; 86: $1227-1234$

4 Kirklin JK, Naftel DC, Kormos RL et al. Second INTERMACS annual report: more than 1000 primary left ventricular assist device implants. J Heart Lung Transplant 2010; 29: 1 -10

5 Crow $S$, John R, Boyle A et al. Gastrointestinal bleeding rates in recipients of nonpulsatile and pulsatile left ventricular assist devices. J Thorac Cardiovasc Surg 2009; 137: 208 - 215

6 Aggarwal A, Pant R, Kumar $S$ et al. Incidence and management of gastrointestinal bleeding with continuous flow assist devices. Ann Thorac Surg 2012; 93: 1534-1540

7 Uriel N, Pak SW, Jorde UP et al. Acquired von Willebrand syndrome after continuous-flow mechanical device support contributes to a high prevalence of bleeding during long-term support and at the time of transplantation. J Am Coll Cardiol 2010; 56: 1207-1213

8 Wever-Pinzon 0 , Selzman $\mathrm{CH}$, Drakos SG et al. Pulsatility and the risk of nonsurgical bleeding in patients supported with the continuous-flow left ventricular assist device HeartMate II. Circ Heart Fail 2013; 6: $517-526$

9 Heyde EC. Gastrointestinal bleeding in aortic stenosis. N Eng J Med 1958; 259: 196

10 Demirozu ZT, Radovanceivic $R$, Hochman LF et al. Arteriovenous malformation and gastrointestinal bleeding in patients with Heartmate II left ventricular device. J Heart Lung Transplant 2011; 30: 849-853

11 Pennington DG, Mcbride LR, Peigh PS et al. Eight years experience with bridging to cardiac transplantation. J Thoracic Cardiovasc Surg 1994; 107: $472-481$

12 Draper KV, Huang RJ, Gerson LB. GI bleeding in patients with continuous-flow left ventricular assist devices: a systematic review and metaanalysis. Gastrointest Endosc 2014; 80: 435-446

13 Kushnir VM, Sharma S, Ewald GA et al. Evaluation of GI bleeding after implantation of left ventricular assist device. Gastrointest Endosc 2012; 75: $973-979$

14 Singh G, Albeldawi M, Kalra $S$ et al. Features of Patients with Gastrointestinal Bleeding After Implantation of an Assist Device. Clin Gastr Hepat 2015; 13: $107-114$

15 Tsiouris A, Paone G, Nemeh HW et al. Factors determining post-operative readmissions after left ventricular assist device implantation. Heart Lung Transplant 2014; 33: 1041 - 1047

16 Forest SJ, Bello R, Friedmann $P$ et al. Readmissions after ventricular assist device: etiologies, patterns, and days out of hospital. Ann Thorac Surg 2013; 95: 1276-1281 
17 Sarosiek K, Bogar L, Conn MI et al. An old problem with a new therapy: gastrointestinal bleeding in ventricular assist device patients and deep overtube-assisted enteroscopy. ASAIO J 2013; 59: 384-389

18 Jackson CS, Gerson LB. Management of Gastrointestinal Angiodysplastic Lesions (GIADs): A Systematic Review and Meta-Analysis. Am J Gastroenterol 2014; 109: 474-483

19 Uriel N, Pak SW, Jorde UP et al. Acquired von Willebrand syndrome after continuous-flow mechanical device support contributes to a high prevalence of bleeding during long-term support and at the time of transplantation. J Am Coll Cardiol 2010; 56: 1207-1213

20 Randi AM, Laffan MA, Starke RD. Von Willebrand factor, angiodysplasia and angiogenesis. Mediterr J Hematol Infect Dis 2013: 5 (1)

21 Daly C, Eicthen A, Castanaro C et al. Angiopoeitin-2 functions as a Tie2 agonist in tumor models, where it limits the effects of VEGF inhibition. Cancer Res 2013; 73: 108 - 118
22 Starke RD, Ferraro F, Paschalaki KE et al. Endothelial von Willebrand factor regulates angiogenesis. Blood 2011; 117: $1071-1080$

23 Veyradier A, Balian A, Wolf $M$ et al. Abnormal von Willebrand factor in bleeding angiodysplasias of the digestive tract. Gastroenterology 2001; 120: 346 - 353

24 Hoog CM, Brostrom O, Lindahl TL et al. Bleeding from gastrointestinal angioectasias is not related to bleeding disorders- a case control study. BMC Gastroenterol 2010; 10: 113

25 Junquera F, Saperas E, de Torres I et al. Increased expression of angiogenic factors in human colonic angiodysplasia. Am J Gastroenterol 1999; 94: 1070 - 1076

26 Ge ZZ, Chen HM, Gao YJ et al. Efficacy of thalidomide for refractors gastrointestinal bleeding from vascular malformation. Gastroenterology 2011; $14: 1629-1637$

27 Laine L, Takeuchi K, Tarnawski A. Gastric mucosal defense and cytoprotection: Bench to bedside. Gastroenterology 2008; 135: 41-60 